\title{
Les communautés religieuses au Québec (1837-1914)
}

\section{Claude Galarneau}

Volume 36, 1969

URI : https://id.erudit.org/iderudit/1007291ar

DOI : https://doi.org/10.7202/1007291ar

Aller au sommaire du numéro

Éditeur(s)

Les Éditions Historia Ecclesiæ Catholicæ Canadensis Inc.

ISSN

0318-6172 (imprimé)

1927-7067 (numérique)

Découvrir la revue

Citer cet article

Galarneau, C. (1969). Les communautés religieuses au Québec (1837-1914).

Sessions d'étude - Société canadienne d'histoire de l'Église catholique, 36, 13-19.

https://doi.org/10.7202/1007291ar

Tous droits réservés @ Les Éditions Historia Ecclesiæ Catholicæ Canadensis Inc., 1970
Ce document est protégé par la loi sur le droit d'auteur. L’utilisation des services d'Érudit (y compris la reproduction) est assujettie à sa politique d'utilisation que vous pouvez consulter en ligne.

https://apropos.erudit.org/fr/usagers/politique-dutilisation/ 


\section{Les communautés religieuses au Québec (1837-1914) *}

La remise en question qui confronte l'ensemble de l'humanité depuis la fin de la Seconde Guerre mondiale n'a pas épargné la vie religieuse, et l'Église catholique a pour sa part procédé à un aggiornamento au Concile de Vatican II. Les Églises nationales ont évidemment emboîté le pas et sont en train d'essayer d'adapter la pastorale et les institutions ecclésiales à la mesure des transformations profondes qu'ont subies les sociétés. Cela ne va pas sans difficulté et la prise de conscience qui se fait chez les individus autant que dans les collectivités témoigne de l'ampleur de la tâche. Les communautés religieuses, quant à elles, sont parfois conduites à s'interroger sur leur existence même, ce qui se traduit chez leurs membres par des défections nombreuses, voire même par de véritables hémorragies. Il n'est donc pas étonnant que la Société canadienne d'Histoire de l'Église catholique ait proposé à ses membres d'étudier quelques aspects de l'histoire des communautés religieuses au Québec dans la seconde moitié du XIX ${ }^{\bullet}$ siècle, soit de 1837 à 1914, l'année 1837 étant celle qui a vu arriver la première communauté depuis la fin du Régime français. Comme les autres communications porteront sur l'histoire de quelques communautés de la ville de Québec, il m'a semblé qu'il serait utile d'esquisser d'abord une étude d'ensemble de l'établissement des communautés au Québec pour cette période, étude qui, à ma connaissance, n'a pas encore été faite. Ce sera une tentative d'évaluation globale, avec des données chiffrées sur le nombre de communautés qui se sont implantées au Québec. La mesure n'est pas le tout de l'histoire, mais toute histoire doit autant que possible utiliser la mesure comme démarche préalable.

A la fin du Régime français, les communautés religieuses sont peu nombreuses : on en compte neuf dont quatre d'hommes : le Séminaire de Québec, les Jésuites, les Récollets et les Sulpiciens, et cinq de femmes : les Ursulines, les Augustines Hospitalières, les Hospitalières de Saint-Joseph, les Dames de la Congrégation et les Sœurs Grises de Montréal. Les Jésuites et les Récollets disparaissent avec le changement d'allégeance, puisque l'Angleterre leur refuse le droit de se recruter. Il n'est pas davantage question de faire venir des prêtres séculiers ou des religieux d'Europe. Les évêques de Québec ne pourront accepter que

\footnotetext{
* Nous entendons par communautés tous les groupes de prêtres séculiers, de religieuses, de religieux prêtres ou frères qui se sont établis au Canada.
} 
deux prêtres français avant 1793. A partir de ce moment, l'Angleterre ayant accordé l'asile à huit mille prêtres émigrés de France, les portes du Bas-Canada s'ouvrent et cinquante et un prêtres émigrés viennent s'installer au pays, dont quarante y demeurent. Ce qui a augmenté le clergé canadien d'un tiers en l'espace de dix ans, puisqu'il n'y avait que 146 prêtres en 1790 . C'étaient des hommes jeunes, très instruits ${ }^{1}$ et qui avaient été triés sur le volet par Mgr de la Marche et Monsieur Émery. Pendant la Révolution et l'Empire, Mgr Hubert et Mgr Plessis tentent d'obtenir des Trappistes et des Jésuites français, mais en vain ${ }^{2}$. Entre 1815 et 1837, les Sulpiciens font venir neuf Messieurs de Paris cependant qu'un seul prêtre séculier arrive pendant la même période, l'abbé Ginguet ${ }^{3}$. Quelques autres prêtres ou évêques français visiteront à l'occasion Québec et Montréal, mais à ma connaissance, il n'y aurait eu qu'une tentative pour amener des religieux français au Bas-Canada. Monsieur Lartigue, lors de son voyage à Londres et à Paris avec Mgr Plessis en 1819-1820, alla frapper chez les Ignorantins, qui ne purent lui promettre de sujets avant que la France n'en soit d'abord pourvue. Mais, à cette occasion, Mgr Plessis ne demanda pas de permission à Londres pour faire venir des Frères, au grand mécontentement de Lartigue ${ }^{4}$. D'autre part, aucune communauté canadienne n'a encore vu le jour depuis la fondation de Mère d'Youville. Enfin, après dix années de négociations entre les Sulpiciens de Montréal et les Frères de la Doctrine chrétienne de Paris, les premiers Frères français arrivent à Montréal en 1837. C'est le début d'une longue histoire et de lendemains prometteurs pour les communautés religieuses.

Mgr Bourget devient évêque de Montréal en 1840 et il passe vite en France chercher des communautés de religieuses, de religieux Pères et Frères, tout en suscitant la fondation de plusieurs communautés canadiennes. Cette fois, ce sont les Sulpiciens qui s'inquiètent du dynamisme de Mgr Bourget. Monsieur Quiblier écrit à son supérieur de Paris, Monsieur Carrière, qu'il ne peut suivre Mgr Bourget tellement ce dernier " taille de la besogne ${ }^{5}$ ». C'est que les Sulpiciens, tout-puissants seigneurs à Montréal depuis longtemps, craignent la concurrence des Jésuites pour leur collège ${ }^{6}$. Quiblier va même jusqu'à dire que le clergé de Montréal « est mécontent de toutes ces importations d'Oblats, de

1 Voir N.-E. Dionne, Les ecclésiastiques et les royalistes français réfugiés au Canada à l'époque de la Révolution (1791-1802), Québec, 1905, XIX-447 p.; C. Galarneau, La France devant l'opinion canadienne (1760-1815), p. 281-301, 330-347, 1969, thèse dactyl., XLII-567 p.

2 Voir C. Galarneav, op. cit., p. 290-293.

3 Voir J. Huston, Le Répertoire national, vol. I, p. $347, \mathrm{n}^{\circ} 1$.

4 ACAM, Journal de voyage de Mgr J.-J. Lartigue en Europe (1819-1820), p. $44,57,82,91,128$.

5 ASSP, Lettre de Quiblier à Carrière, 23 avril 1842.

6 Ibid., 27 sept. 1842. 
Jésuites, etc. ${ }^{7}$ ». Le double mouvement de fondations canadiennes et de recrutement à l'étranger va néanmoins se continuer jusqu'à nos jours. Selon l'état actuel de mes recherches, on peut ainsi dénombrer les communautés établies au Canada et au Québec de 1815 à 1914 :

1. 127 c. pour l'ensemble du Canada de 1815 à 1914, se répartissant comme suit :

85 c. de femmes

42 c. d'hommes

37 c. fondées au Canada

68 c. venues de France

22 c. venues d'autres pays

2. Pour le Québec seulement: 89 c. en tout, se répartissant comme suit :

57 c. de femmes

32 c. d'hommes

28 c. fondées au Québec (dont 2 d'hommes seulement)

53 c. venues de France (dont 29 de femmes et 24 , d'hommes)

8 c. venues d'autres pays ${ }^{8}$

Si l'on examine d'autre part - toujours pour le seul Québec - la répartition chronologique décennale des communautés, on voit que 14 communautés sont apparues entre 1837 et 1849 et 33 entre 1900 et $1914^{\circ}$. Pour chacune de ces deux périodes, qui sont les plus fécondes on compte 6 fondations canadiennes-françaises et 8 communautés venues de France pour la première, et 6 fondations canadiennes-françaises et 24 communautés venues de France pour la seconde ${ }^{10}$. Ce dernier chiffre me paraît s'expliquer par le combisme, qui a obligé les communautés françaises à séculariser leurs membres ou à les envoyer dans les pays étrangers. Le Québec a profité largement de cet exil puisqu'il est arrivé 24, communautés françaises pendant cette décennie, alors qu'il en était venu 29 entre 1837 et 1899. Au surplus, plusieurs autres communautés françaises déjà établies au Québec avant 1900 ont alors reçu des dizaines, voire même plusieurs centaines de sujets, comme l'étude récente de l'un de mes étudiants vient de le montrer : les Frères des Écoles chrétiennes, au Québec depuis 1837, ont en effet accueilli 221 de leurs Frères français entre 1904 et $1908^{11}$.

7 Ibid., 28 juillet 1843.

8 Voir le Tableau I.

9 Voir le Tableau II.

10 Voir les Tableaux III et IV.

11 André Dubuc, Le combisme et les Frères des Ecoles chrétiennes au Canada français (1904-1908), Institut d'histoire, 1969, XIII-111 p., mémoire de D.E.S. dactyl., p. 33 et suiv. 
Si l'on tente d'expliquer les circonstances qui ont empêché le recrutement des clercs pendant soixante-dix-sept années après la fin du Régime français et qui ont vu 89 fondations dans les soixante-dix-sept années suivantes, on arrive à quelques constatations et à beaucoup d'hypothèses. Les besoins d'un pays immense, peu peuplé en 1760 mais en augmentation constante, un clergé pauvre en nombre et qui se recrute très faiblement, montrent la place qu'il y avait à remplir. Pourtant, les efforts répétés des évêques pendant trois quarts de siècle sauf l'épisode des prêtres émigrés de la Révolution - ont été vains. Aucune communauté canadienne ou française n'a vu le jour avant 1837. A partir de ce moment, les fondations canadiennes et françaises vont se faire à un rythme continu et même accéléré pour la dernière décennie. La coïncidence paraît certaine entre l'arrivée de Mgr Bourget comme évêque de Montréal et les premières fondations; il en a recruté ou fondé une bonne quinzaine. La division des diocèses de Québec et de Montréal a poussé les nouveaux évêques à agir de la même façon, les curés et leurs paroissiens ont quelquefois pris l'initiative. D'autre part, la conjoncture politique française est responsable de la forte poussée de la dernière décennie. Si l'on considère un instant l'évolution globale de la société canadienne-française de 1760 à 1914, on est frappé des coïncidences qui entourent les années 1837-1840, qui marquent la défaite du leadership des laïcs, ıelayé par le leadership clérical, et les fondations multipliées des communautés religieuses.

Quant aux secteurs de la vie québecoise qui ont profité de l'établissement des communautés religieuses, ils sont multiples. Le service des paroisses, l'enseignement dans les collèges classiques et les juniorats, la prédication et les confréries ont été les principaux champs d'activité des religieux prêtres; l'assistance publique dans les hôpitaux, les hospices. les asiles, ceux des religieuses et des religieux frères; l'enseignement dans les écoles primaires, dans les écoles normales, dans les écoles spéciales de commerce, d'agriculture et de métiers, ceux des Soeurs et des Frères également. C'était d'ailleurs les œuvres qui avaient toujours été dévolues à l'Église depuis les premiers siècles du christianisme et que nul ne songeait à lui disputer au Canada.

On peut dresser un bilan de cette évaluation sommaire des communautés religieuses au Québec et tracer quelques voies d'approche. En 1837, le Québec compte deux diocèses, environ 400 prêtres et sept communautés $^{12}$; en 1914, il y a trois archidiocèses, onze diocèses, environ 3,000 prêtres et quelques milliers de religieux frères et de religieuses répartis en 95 communautés. Les prêtres se seraient ainsi

12 Selon le Canada ecclésiastique de 1911, p. 5. 
multipliés par 7.5 et les communautés par $15.8^{13}$. Il y aurait lieu d'entreprendre bien d'autres recherches statistiques pour les confronter ensuite avec la progression démographique des populations catholiques. Il faut encore établir la carte des points d'implantation des communautés, de leur recrutement géographique et social, de leur essaimage à l'intérieur et à l'extérieur du Québec. A ce dernier titre, je citerai encore l'exemple des Frères des Écoles chrétiennes qui ont envoyé aux États-Unis 224 sujets canadiens-français avant 1903. L'étude de l'influence des communautés françaises sur la culture et surtout sur la conservation et l'enrichissement de la langue des Canadiens français serait encore un aspect important à considérer. Nous avons besoin de solides monographies sur l'histoire des communautés canadiennes et françaises, sans oublier de faire d'abord l'inventaire de ce qui a été publié de valable sur chacune d'elles. Ces études nous informeraient de l'évolution interne des communautés, de leur activité variée dans les domaines religieux, éducatif, de l'assistance publique, de même que de leur situation dans la vie sociale, économique, politique et intellectuelle. Si le nombre a quelque importance, il est certain que la multiplication des clercs a eu des incidences nettes sur la montée du cléricalisme. Les religieux ont comblé des vides immenses et rendu de signalés services, mais, de par leur place devenue prépondérante dans des secteurs vitaux comme ceux de l'éducation et de l'assistance publique, ils ont oublié de préparer les laïcs à jouer leur rôle, si bien qu'au moment où la société subissait des changements profonds, notre collectivité s'est retrouvée pratiquement sans cadre pour prendre la relève.

Certes, l'étude de ces différents aspects historiques et sociologiques est amorcée, quoiqu'en ordre dispersé. Ce n'est pas le lieu d'en faire l'inventaire; aussi, je souhaite que tous les chercheurs, historiens, sociologues et autres spécialistes se rencontrent et travaillent de façon convergente dans la pluridisciplinarité, avec la coopéraiton des communautés religieuses elles-mêmes.

\author{
Claude Galarneau, \\ Directeur de l'Institut d'Histoire, \\ Université Laval.
}

13 Selon Louis-Edmond Hamelin, le nombre d'habitants par prêtre est passé de 1,830 en 1834 à 1,080 en 1850 , à 510 en 1880 et à 652 en 1910 ; dans - Evolution numérique séculaire du clergé au Québec *, Recherches sociographiques, vol. II, $\mathbf{n}^{\circ} 2$ (avril-juin 1961), p. 225. 
TABLEAU I

Communautés établies au Canada et au Québec de 1815 à 1914

\begin{tabular}{|l|c|c|}
\hline & Canada & Québec \\
\cline { 2 - 3 } Toutes les communautés & 127 & 89 \\
Fondations canadiennes & 37 & 28 \\
Communautés venues de France & 68 & 53 \\
Communautés venues d'autres pays & 22 & 8 \\
\hline
\end{tabular}

TABLEAU II

Ordre chronologique décennal (1837-1914)

(Québec seulement)

\begin{tabular}{|c|c|c|c|}
\hline Années & Hommes & Femmes & Total \\
\cline { 1 - 3 } $1837-1849$ & 5 & 9 & 14 \\
$1850-1859$ & 0 & 7 & 7 \\
$1860-1869$ & 2 & 3 & 5 \\
$1870-1879$ & 3 & 3 & 6 \\
$1880-1889$ & 8 & 5 & 13 \\
$1890-1899$ & 4 & 7 & 11 \\
$1900-1914$ & 10 & 23 & 33 \\
\hline
\end{tabular}


TABLEAU III

Fondations québecoises (1840-1914)

\begin{tabular}{|c|c|c|c|}
\hline Années & Hommes & Femmes & Total \\
\hline $1840-1849$ & & 6 & 6 \\
$1850-1859$ & & 5 & 5 \\
$1860-1869$ & & 2 & 2 \\
$1870-1879$ & & 2 & 2 \\
$1880-1889$ & & 3 & 3 \\
$1890-1899$ & & 4 & 4 \\
$1900-1914$ & 2 & 4 & 6 \\
\hline
\end{tabular}

TABLEAU IV

Communautés françaises (1837-1914)

(Québec seulement)

\begin{tabular}{|c|c|c|c|}
\hline Années & Hommes & Femmes & Total \\
\hline $1837-1849$ & 5 & 3 & 8 \\
$1850-1859$ & 0 & 2 & 2 \\
$1860-1869$ & 1 & 1 & 2 \\
$1870-1879$ & 2 & 1 & 3 \\
$1880-1889$ & 5 & 2 & 7 \\
$1890-1899$ & 4 & 3 & 7 \\
$1900-1914$ & 7 & 17 & 24 \\
\hline
\end{tabular}

